\title{
Tumor Necrosis Factor Receptor Superfamily Member 13B
}

National Cancer Institute

\section{Source}

National Cancer Institute. Tumor Necrosis Factor Receptor Superfamily Member 13B. NCl Thesaurus. Code C127903.

Tumor necrosis factor receptor superfamily member 13B (293 aa, $32 \mathrm{kDa}$ ) is encoded by the human TNFRSF13B gene. This protein plays a role in cytokine binding and lymphocyte activation. 